\title{
A COMPARATIVE STUDY BETWEEN SURGICAL OUTCOMES IN OESOPHAGEAL ATRESIA WITH DISTAL TRACHEO-OESOPHAGEAL FISTULA REPAIR WITH LIGATED AND PRESERVED AZYGOS VEIN
}

\author{
Pramod Kumar Mohanty1, Udayabhanu Dhal², Pradeep Kumar Jena ${ }^{3}$, Hiranya Kishor Mohanty4, Gadadhar Sarangi ${ }^{5}$
}

${ }_{1}^{1}$ Associate Professor, Department of Paediatric Surgery, SVPPGIP, Cuttack, Odisha, India.

${ }^{2}$ Senior Resident, Department of Paediatric Surgery, SVPPGIP, Cuttack, Odisha, India.

3 Professor, Department of Paediatric Surgery, SVPPGIP, Cuttack, Odisha, India.

4 Professor, Department of Paediatric Surgery, SVPPGIP, Cuttack, Odisha, India.

${ }^{5}$ Retd. Professor and Director, Department of Paediatrics, Hi-Tech Medical College, BBSR, Bhubaneswar, Odisha, India.

\section{ABSTRACT}

\section{BACKGROUND}

Oesophageal atresia and tracheo-oesophageal fistula are some of the most challenging surgical problems in neonates. Improvement in surgical techniques and peri-operative management made the survival better. It will be worthwhile to study the anomaly and improve different techniques of surgical approach for manoeuvrability and outcome.

The objective of this study is to evaluate the results of preservation of Azygos vein during the operation for TEF repair.

\section{MATERIALS AND METHODS}

This comparative study was carried out in the Department of Paediatric Surgery of SVP Postgraduate Institute of Paediatrics, SCB Medical College, Cuttack, Odisha over a period of two years from Sept 2013 - 2015. Since the study duration was short, we had to limit the sample size for convenience. 60 full-term neonates with TEF having birth weight $>2$ Kgs., ages of presentation $<2$ days and without mechanical ventilation were selected for the study.

Total of 60 cases on the study were divided into three groups and each group having 20 (Group A, B, C). Group A (n= 20) where azygos vein was ligated and divided, Group $B(n=20)$ where azygos vein was preserved, and anastomosis was done lateral to vein and Group C $(n=20)$ where azygos vein was preserved, and anastomosis was done medial to vein. The outcome of study was compared using student's " $\mathrm{t}$ " test and Chi-square test.

\section{RESULTS}

60 cases of TEF with EA were divided into 3 groups randomly before operation. Group A (20) ligating the Azygos vein, Group B without ligating the vein and performing lateral anastomosis and Group C with preserved Azygos vein and medial anastomosis. Results were compared with operation time, development of pneumonitis, anastomotic leaks and mortality. All the three groups did not have statistically significant difference in the above parameters.

\section{CONCLUSION}

Though statistically not different, the operation time is marginally shorter in Group A and complications are marginally better in Group B and C. Medial anastomosis preserving the Azygos vein should be preferred, as it does not obstruct the natural venous drainage.

\section{KEY WORDS}

EA (Oesophageal Atresia), TEF (Tracheo-Oesophageal Fistula), IVC (Inferior Vena Cava), SVC (Superior Vena Cava), Azygos Veins. HOW TO CITE THIS ARTICLE: Mohanty PK, Dhal U, Jena PK, et al. A comparative study between surgical outcomes in oesophageal atresia with distal tracheo-oesophageal fistula repair with ligated and preserved azygos vein. J. Evolution Med. Dent. Sci. 2018;7(38):4221-4226, DOI: 10.14260/jemds/2018/942

\section{BACKGROUND}

Oesophageal atresia and tracheo-oesophageal fistula is one of the most challenging surgical problems in neonates. Improvement in surgical techniques and peri-operative management made the survival better. It will be worthwhile to study the anomaly and improve different techniques of surgical approach for manoeuvrability and outcome.

In comparison to other GI anomalies, oesophageal anomaly is fairly uncommon. The overall incidence is approximately 1 in 3500 to 4500 live births. ${ }^{1}$

'Financial or Other Competing Interest': None.

Submission 13-08-2018, Peer Review 05-09-2018,

Acceptance 12-09-2018, Published 17-09-2018.

Corresponding Author:

Dr. Gadadhar Sarangi,

The Child, B. K. Road,

Ranihat, Cuttack-753001, Odisha, India.

E-mail: drgadadhars@gmail.com

DOI: $10.14260 /$ jemds $/ 2018 / 942$

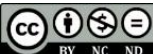

The estimated incidence of EA in India is $18000{\text { per year. }{ }^{2}}^{2}$ Pathogenesis of EA remains unknown. Early disturbances in organogenesis that results in EA also affects other organ systems. Overall incidence of associated anomaly is $50-70 \%$ and includes cardiovascular, genitourinary, gastrointestinal, musculoskeletal, CNS and VACTERL anomalies which bears prognostic significance. ${ }^{3}$ Other less frequent conditions like tracheomalacia, spina bifida and exomphalos are associated with EA. ${ }^{4}$

Numerous classification systems have been proposed. Among these the most useful and practical is simple anatomical description of anomalies. Many institutes and surgeons still use gross classification. Most common variety is EA with distal tracheo-oesophageal fistula $(84 \%)^{5}$ and least common is EA with a fistula to both pouches (1\%).

First published case of an EA with TEF treated by fistula ligation and primary oesophageal anastomosis was performed by Robert Shaw of Dallas, Texas in 1939. Prior to 1939, EA was uniformly fatal throughout the world. In 1939 
almost simultaneously Dr. Logan Leven of St. Paul and Dr. William Ladd of Boston gave first complete surgical success, but they did primary gastrostomy followed by delayed primary repair. ${ }^{6}$ On March 15, 1941, first successful primary repair was performed by Cameron Haight of Ann Arbor using left extrapleural approach. ${ }^{7}$ In 1943, Haight revised his procedure to right extrapleural approach.

In India, the first successful operation was performed by Dr. S. K. Chaterjee in 1964 at Ramakrishna Mission Seva Pratisthan. Since then so many technical advances has been made like conventional extrapleural approach and transpleural approach, $8,9,10$ end-to-side anastomosis, ${ }^{11}$ anastomosis reinforced with pleural patch, thoracoscopic repair,12,13 oesophageal replacement with colon, small bowel and stomach and more recent efforts like tissue engineering. ${ }^{6}$

Advances in improved paediatric nursing care, anaesthetic techniques, intensive care facility with ventilator support, better antibiotics and better suture material, the result of EA with TEF repair has improved dramatically.

Other than the above, result also depends on many factors ${ }^{13,14}$ like birth weight of patient, age at presentation, associated anomaly, oesophageal gap length, physiological status of the patient, ventilator dependence and surgical techniques. ${ }^{15}$

The complication of primary repair are major or minor leaks, recurrent TEF and significant strictures. Incidence of leakage varies widely from 4 to $36 \% \cdot 8,16,17,18$ Anastomotic leaks as reported in several Indian series, which varies from 16 - 35\%.16,17,19 Leak rate in long gap EA with TEF has been reported to be $100 \% .{ }^{4}$ Mortality rate after anastomotic leak, however, are very high in developing as well as developed countries. Hence, anastomotic leak directly influences the outcome. 20

The standard procedure followed at present is right posterolateral thoracotomy by extrapleural approach ligation of Azygos vein encountered in right lateral aspect of oesophagus arching forward at the level of T4 with the idea of easy access to atretic-oesophageal ends and fistula and also for making anastomosis comfortably.21,22,23

Azygos vein forms an important channel connecting the superior and inferior vena cava. It is formed by two roots, medial and lateral roots. Medial root is from IVC at the level of renal vein and lateral is formed by right subcostal and right ascending lumbar veins. Two roots joined at level of T12 to form Azygos vein. It pierces diaphragm and ascends in the right paravertebral area upto $\mathrm{T} 4$, where it arches forward over root of right lung and ends by joining SVC. The tributaries are right superior intercostal veins, $4^{\text {th }}$ to $11^{\text {th }}$ right posterior intercostal veins, hemiazygos vein, accessory hemiazygos vein, right bronchial vein, several oesophageal, mediastinal and pericardial veins.

The concept of Azygos vein preservation restores the normal mediastinal anatomy and normal venous drainage of oesophagus and bronchus, thereby improving post-operative wound healing. ${ }^{24,25}$ Whether it has any advantage in terms of technical issues, operating time, post-operative leak and mortality is the interest of the present study.

\section{Aims and Objectives}

The comparative prospective study was carried out to compare the result of ligation of Azygos vein with that of preservation of the vein with anastomosis lateral and medial to vein in three comparable groups in terms of operating time, post-operative pneumonia, post-operative leak and mortality.

\section{MATERIALS AND METHODS}

This is a comparative prospective study conducted over a period of two years from Sept 2013 to Sept 2015 in the Department of Paediatric Surgery, SVP Postgraduate Institute of Paediatrics, SCB Medical College, Cuttack, Odisha.

\section{Subjected for Study}

The patients with classical oesophageal atresia with distal tracheo-oesophageal fistula (Gross type C) managed by extrapleural approach and primary single layer anastomosis were enrolled for study. 60 patients were selected for this study and assigned in 3 groups and each group having 20 patients (Group A, B, C)-

\section{Group A (n= 20)}

In whom, Azygos vein was ligated and divided.

\section{Group B (n= 20)}

Where Azygos vein was preserved, and oesophageal anastomosis was done lateral to the vein.

\section{Group C $(n=20)$}

Where Azygos vein was preserved, and anastomosis was done medial to the vein.

\section{Inclusion Criteria}

- $\quad$ Birth weight $\geq 2 \mathrm{~kg}$.

- Full-term gestation.

- Age at presentation $<2$ days.

- Ability to maintain adequate oxygen saturation preoperatively without mechanical ventilation.

\section{Exclusion Criteria}

- $\quad$ Birth weight $<2 \mathrm{~kg}$.

- Preterm baby.

- Age at presentation $>2$ days.

- Ventilator dependent patients.

- Major cardiac anomaly.

- Other types of EA (Gross type A, B, D, E, F).

The three groups were comparable with respect to gestational age, birth weight, sex, age at presentation, associated anomalies and gap between pouches after mobilisation.

The parameters used to compare the results in the three groups were operating time, early post-operative complications like Pneumonitis, Anastomotic leak and Mortality.

\section{Statistical Analysis}

The outcome in study groups are compared using SPSS software version 6.1 to calculate student's " $t$ " test and Chisquare test. The value is considered significant, when " $\mathrm{P}$ " value is less than or equal to 0.05 .

\section{Pre-Operative Assessment}

All patients were subjected to detailed history and a thorough clinical examination. Attention was given to find out the 
associated anomalies. All patients were kept nil per orally with intravenous fluid containing an adequate glucose concentration $(10 \%$ glucose $)$ and prophylactic broadspectrum antibiotics (Ampicillin, gentamicin).

Newborn is positioned in upright sitting posture or headup prone position with the head elevated approximately $45^{\circ}$. A $10 \mathrm{Fr}$. feeding tube is placed nasally or orally into upper pouch and is connected to continuous low-pressure suction device.

Laboratory tests like $\mathrm{Hb} \%$, Serum bilirubin, Liver function tests, Serum electrolyte and Plain x-ray showing recoiling of tube in the upper pouch, infantogram to detect vertebral and limb anomalies and USG for other congenital anomalies were performed.

The parents were fully explained about the nature of congenital anomaly. A diagram is invaluable for explaining not only the pathologic anatomy and intended repair, but also the possible complications. Their consent for treatment was obtained and the discussion with them was documented in appropriate details on baby's medical record.

\section{Surgical Techniques}

After GA with endotracheal intubation, infant is positioned for standard right-sided postero-lateral thoracotomy with left lateral position. Right arm is extended above head and head is slightly flexed. A bolster is placed underneath left lower chest. A curved skin incision is made $1 \mathrm{~cm}$ below the palpable tip of scapula extending from midaxillary line to paravertebral line. Latissimus dorsi was divided posteriorly and the fascia lying just posterior to posterior margin of serratus was divided anteriorly. Scapula is then lifted away from chest wall and held with stay suture. The chest was entered through the $4^{\text {th }}$ ICS. Posterior mediastinum was reached by gently sweeping the parietal pleura off the endothoracic fascia by wet pledges. Azygos vein was seen crossing from right to left. Infants in whom anastomosis is made lateral to Azygos vein was left undisturbed. In other two groups, a nick was given in the endothoracic fascia just below Azygos. A blunt right-angled forceps passed beneath azygos arch and a tunnel was made by stripping the endothoracic fascia above it. Vein was ligated and divided in one group and preserved in other. Lower oesophageal pouch was identified, mobilised a little. Fistula with trachea identified, divided and tracheal end closed by interrupted sutures (4-0 polyglactin, absorbable) or transfixed and divided. Upper pouch was identified by asking anaesthetist to push the feeding tube a little and mobilised. Gap between the two mobilised ends were noted. In Azygos ligated group, direct anastomosis between both ends was done. In other two groups, the lower oesophageal end was passed either above (if anastomosis was planned lateral to Azygos) or through tunnel beneath azygos (if anastomosis was planned medial to azygos). Anastomosis was done with single layer interrupted end-to-end fashion with 4-0 polyglactin. A transanastomotic feeding tube (5-7 ft) was placed for postoperative feeding. A retropleural drain was given.

Gap between the mobilised ends of oesophagus, type of operation (ligated and divided azygos vein, preserved azygos vein with anastomosis lateral to vein or medial to vein), operative time (starting from skin incision to completion of wound closure) and intraoperative complications were noted.

\section{Post-Operative Care}

Post-operative elective mechanical ventilation was continued for 1 - 2 days. Post-operative fluid, antibiotic and analgesic was given to all patients. Feeding through transanastomotic tube was started after 24 to 48 hours depending upon the general condition. Chest radiograph was obtained on day 1 and day 5 for possibility of pneumothorax and pneumonia. Chest tube and bag was evaluated every day. Minor leaks were identified by frothy secretions in the drain without deterioration of general condition, while major leaks were suspected by profuse secretion with deterioration of general condition in the form of increased respiratory distress and pneumonia. On post-operative day 7 , water soluble contrast oesophagogram was done and oral feeds started if there was no leak. Chest tubes were removed on day 8. Patients were discharged after removal of sutures on day 10. In case of leak, both major and minor leaks were treated conservatively with PPN with chest tube in situ. Feeding was delayed till leak has stopped (16 days in minor leak, 28 days for major leak) and so the chest tube removal and discharge.

\section{Advice on Discharge-}

- $\quad$ Feeding of baby in upright posture.

- Pro-kinetics and H2 blocker to lessen reflux.

- Positioning of baby in bed in prop-up position.

- Immunisation of baby as per schedule.

- Follow-up after one month.

\section{Follow-Up}

In follow-up, patients were assessed at $1 \mathrm{~m}, 3 \mathrm{~m}$ and thereafter yearly. Assessment was made for child's general condition, growth, healing at surgical site, reflux, swallowing function and respiratory issues.

Radiological assessment of oesophagus (contrast oesophagogram) was done in few cases with history of dysphagia, regurgitation, coughing, choking, cyanosis after feed and growth failure. Subsequent endoscopic evaluation and dilatation was done in selected cases as identified.

\section{RESULTS}

During this 2 years period, total indoor admission was 39,851 . Out of this, 3911 (9.81\%) patients were admitted to Paediatric Surgery Department (male $=2735$, female $=1166$ ) During this period, 78 (1.99\% of total indoor admission in paediatric surgery) cases of EA with TEF were operated. Among 78 cases 60 cases of EA with distal TEF were enrolled in this study. Cases with preterm birth weight $<2 \mathrm{~kg}$, age at presentation more than 2 days, ventilator dependent patients, major cardiac anomaly and other types of EA (Type A, B, D, E, F) were excluded from the study.

The 60 cases included in present study were randomly assigned into 3 groups. Group A $(n=20)$ where azygos vein was ligated and divided and Group B $(n=20)$ where azygos vein was preserved, and anastomosis was done lateral to vein and Group C $(n=20)$ where azygos vein was preserved and anastomosis was done medial to vein.

These three groups were comparable in terms of GA, birth weight, sex, age at presentation, associated anomalies and gap length after mobilisation.

The sex incidence in this study showed male preponderance. Among 60 cases 33 cases were male (55\%), whereas 27 cases were females (45\%). 
The mean age of presentation in three groups was less than 48 hours and were comparable with Group A 38.20 hours, Group B 42.18 hours and Group C 40.27 hours. Group A 7 cases, Group B 6 cases and Group C 7 cases had associated anomalies.

In this study most commonly affected anomalies were GUS ( 8 cases, $13.3 \%$ ), Limb anomalies ( 6 cases, 10\%), GIT (3 cases, $5 \%$ ) and Cleft palate (3 cases, $2 \%$ ). Major cardiac anomalies ware excluded from the study.

Birth weight of all the three groups were more than $2 \mathrm{~kg}$ with $2.38 \mathrm{~kg}$ in Group A, $2.56 \mathrm{~kg}$ in Group B and $2.43 \mathrm{~kg}$ in Group C.

Mean gap between two mobilised oesophageal ends were $<2 \mathrm{~cm}$. Anastomosis was done without tension or with minimal tension, which is a major factor for post-operative leak and mortality. The three groups were comparable in terms of gap between two ends after mobilisation with 1.4 cms in Group A, $1.26 \mathrm{cms}$ in Group B and $1.36 \mathrm{cms}$ in Group C.

The results of the study were compared between three groups in terms of operative time, pneumonitis, anastomotic leak and mortality.

\section{Operative Time}

The mean operative time for Group A was 72 minutes, Group B was 75 minutes and Group $C$ was 81 minutes.

The operative time was shorter in azygos ligation group than preserved group. Among the preserved group, operative time was less in anastomosis lateral to azygos than medial to azygos group. This difference in operative time was not statistically significant $(\mathrm{p}>0.05)$.

\section{Post-Operative Pneumonitis}

Post-operative pneumonitis was higher in Group A (8 cases, $13.3 \%$ ) in comparison to Group B (6 cases, $10 \%$ ) and Group C (5 cases, 8\%). Among azygos preserved group, pneumonitis was higher in anastomosis done lateral to azygos group. This result was not statistically significant $(p>0.005)$.

\section{Anastomotic Leak}

13 patients developed anastomotic leak, 6 in Group A, 4 in Group B and 3 in Group C. Anastomotic leak was higher in Azygos ligated group than preserved group. There was no statistically significant difference between these 3 groups ( $P>0.005)$. In Group A there was 2 major and 4 minor leaks, in Group B there was 1 major and 3 minor leaks and in Group $\mathrm{C}$ there was 1 major and 2 minor leaks.

\section{Mortality}

There was 8 deaths in this series, 4 in Group A, 3 in Group B and 2 in Group $C$, but was not statistically significant $(\mathrm{P}>0.005)$. All patients with major leak in Group A and one patient with major leak in Group B died. All the minor leak cases were managed conservatively and all of them healed spontaneously. Major leaks were also managed conservatively with PPN. Patients were allowed orally only after complete healing at anastomotic site documented by contrast oesophagography. Severe pneumonitis and septicaemia in patients with major leak contributed to mortality.

During follow-up stricture developed in 4 patients in Group A, 2 patients in Group B and 1 patient in Group C. All stricture patients underwent endoscopic dilatation successfully. 3 in Group A, 5 in Group B and 2 in Group C. A total of 10 patients were lost for follow-up.

\section{DISCUSSION}

The evolution of a congenital abnormality incompatible with life to a condition with a survival rate well over $90 \%$ is a remarkable achievement in case of EA. Now in advent of experienced anaesthetist, better anaesthetic drugs, advanced surgical techniques, suture material, better antibiotic, advanced intensive care facility and better knowledge about pathophysiology EA with TEF has made the survival better.

At present, standard technique is to ligate and divide azygos vein very early in the operation. This is supposed to provide an easy access to the atretic oesophageal ends and fistula and also make the anastomosis comfortable.

The azygos system reflects to the primary objectives of venous system design, to provide multiple routes for blood to return and another is to take the least complicated course from tissue source to the major venous passage. At the beginning of azygos arch, right superior intercostal veins joins it having received the $2^{\text {nd }}, 3^{\text {rd }}$ and $4^{\text {th }}$ posterior intercostal veins. At the level of $4^{\text {th }}$ thoracic vertebra, azygos vein arches above the hilar structure of right lung to enter the SVC with oesophagus medial to it in the posterior mediastinum. Preservation of azygos vein has been found to maintain the mediastinal venous drainage, thereby decreasing the post-operative chest congestion and tissue oedema. Although, oesophageal anastomosis can be made lateral or medial to preserved azygos arch, yet it has been mostly done lateral to arch for ease of the procedure.

In the present study, the patients were randomly assigned into 3 Groups. Group A: Azygos ligated, Group B: Azygos preserved and anastomosis lateral to the vein, Group C: Azygos preserved, and anastomosis performed medial to the vein. All the three groups were comparable with gestational age, birth weight, sex age at presentation, associated anomalies and gap between pouches after mobilisation.

Consistent with the previous studies it was neither found that anastomosis medial to azygos arch was technically difficult nor was the operating time significantly increased. The complication and mortality in azygos preserved Group $(B, C)$, although lower than azygos ligated Group A are not statistically significant $(\mathrm{P}>0.05)$.

\section{Limitation}

Since study duration was short, we had to limit the sample size for convenience.

\section{Summary}

$60 \%$ patients were enlisted for the study and divided into 3 Groups A, B and C randomly for a prospective study over a period of 2 years. Group A: Azygos ligated, Group B: Azygos preserved and anastomosis lateral to the vein and Group $C$ : Azygos preserved, and anastomosis performed medial to the vein. Mean age at presentation was 38 hours in Group A, 42 hours in Group B and 40 hours in Group C. The sex incidence in this study showed male preponderance of 55:45. Average birth weight in Group A is $2.38 \mathrm{~kg}$, in Group B is $2.56 \mathrm{~kg}$ and in Group C is $2.43 \mathrm{~kg}$. Among 60 cases, 20 cases had associated anomalies. Group A 7 cases, Group B 6 and Group 
C 7 cases. The most commonly affected anomalies were GUS ( 8 cases, 13\%), Limb anomalies ( 6 cases, 10\%), GIT ( 3 cases, $5 \%$ ) and Cleft palate ( 3 cases, 5\%). Major cardiac anomalies were excluded from this study. Average gap between two ends after mobilisation was $1.40 \mathrm{~cm}$ in Group A, $1.26 \mathrm{~cm}$ in Group B and $1.36 \mathrm{~cm}$ in Group C. Average operative time was 72 minutes in Group A, 75 minutes in Group B and 81 minutes in Group C. Post-operative pneumonitis was in 8 cases in Group A, in 6 cases in Group B and 5 cases in Group C. Anastomotic leak was seen in 6 cases (2 major and 4 minor) in Group A, in 4 cases (1 major and 3 minor) in Group $B$ and 3 cases (1 major and 2 minor) in Group C. All cases of anastomotic leak including major leaks were managed conservatively. All the major leak patients had received PPN. Among 60 patients post-operative ventilation was required for 28 patients, 11 from Group A, 8 from Group B and 9 from Group C. Average duration of ventilation was less than 48 hours. Patient started transanastomotic feeding after 24 to 48 hours and orally on an average day 7 post-operatively. Those who were having leak, feeding was delayed till leak stopped (16 days for minor leak, 28 days for major leak). One patient in Group A and one in Group B died within 24 hours of surgery. Duration of hospital stay ranged from 10 to 40 days with an average of 16.8 days. Patients were followed for a mean period of 1 year post discharge, 7 patients developed anastomotic stricture which was amenable to dilatation.

\section{CONCLUSION}

In conclusion, the oesophageal anastomosis medial or lateral to preserved azygos vein in EA with TEF does not provide a statistically significant advantage in terms of operative time, post-operative complications like pneumonitis, and leak and mortality over azygos ligated group. Still it is proposed to restore the normal mediastinal anatomy and physiological way of venous drainage by doing anastomosis medial to preserved azygos vein, as it is not technically difficult, nor does it increase the operative time.

\section{REFERENCES}

[1] Ashcraft KW, Holder TM. Oesophageal atresia and Trachea-oesophageal fistula malformation. Surg Clinics of North America 1976;56(2):229-315.

[2] Tandon RK, Sharma S, Sinha CK, et al. Oesophageal atresia: factor influencing survival - experience at an Indian tertiary center. Journal of Indian Association of Pediatric Surgeon 2008;13(1):2-6.

[3] German JC, Mahour GH, Woolley MM. Oesophageal atresia and associated anomalies. Journal of Pediatric Surgery 1976;11(3):299-306.

[4] Filler R, Wesson D, Sigmoid H. Oesophageal atresia and distal trachea oesophageal fistula: associated anomalies \& prognosis in 1980s. Journal of Pediatric Surgery 1989;124(10):1055-9.

[5] Gross RE. The surgery of infancy and childhood. Philadelphia: WB Saunders 1953.

[6] Ladd WE. The surgical treatment of Oesophageal atresia and trachea-oesophageal fistulas. New Eng J Med 1944;230:625-37.

[7] Height C, Towsley HA. Congenital atresia of the oesophagus with trachea-oesophageal fistula: extrapleural ligation of fistula and end to end anastomosis of oesophageal segments. Surg Gynecol Obstet 1943;76:672-88.

[8] Bishop PJ, Kleis MD, Philippart AJ, et al. Transpleural repair of oesophageal atresia with primary gastrostomy: 240 patients treated between 1951 and 1983. Journal of Pediatric Surgery 1985;20(6):823-8.

[9] Singleton AO, Knight MD. Congenital atresia of oesophagus with trachea-oesophageal fistulae. Transpleural operative approach. Ann Surg 1944;119(4):556-71.

[10] Chittmittrapap S, Spitz L, Kiely EM, et al. Anastomotic leakage following surgery for oesophageal atresia. J Pediatr Surg 1992;27(1):29-32.

[11] Sulamaa M, Gripenberg L, Ahvenainen EK. Prognosis and treatment of congenital atresia of oesophagus. Acta Chir Scand 1951;102(2):141-57.

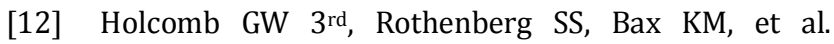
Thoracoscopic repair of oesophageal atresia and tracheoesophageal fistula: a multi institutional analysis. Ann Surg 2005;242(3):422-8. Discussion 428-30.

[13] Bendi G, Choudhury SK, Rao KLN. Oesophageal atresia with tracheaoesophageal fistula: an audit. J Indian Assoc Pediatr Surg 2004; 9:126-130.

[14] Farkash U, Lazar L, Erez I, et al. The distal pouch in Oesophageal atresia - to dissect or not to dissect, that is the question. Eur J Pediatr Surg 2002;12(1):19-23.

[15] Choudhury SR, Ashcraft KW, Sharp RJ, et al. Survival of patients with Oesophageal atresia: influence of birth weight, cardiac anomaly and late respiratory complication. J Pediatr Surg 2001;36:1419-21.

[16] Sharma AK, Kothari SK, Goel D, et al. Morbidity and mortality with respect to gap between two segments in oesophageal atresia. J Indian Assoc Pediatr Surg 1997;2(2):60-70.

[17] Tripathy PK, Rao KLN, Choudhury SK, et al. Lower pouch mobilisation in long gap Oesophageal atresia. J Indian Assoc Pedaitr Surg 2004;9:172-8.

[18] McKinnon LJ, Kosloske AM. Prediction and prevention of anastomotic complication of oesophageal atresia and trachea-oesophageal fistula. J Pedaitr Surg 1990;25(7):778-81.

[19] Chowdhary SK, Rao KLN. Oesophageal atresia with trachea-oesophageal fistula - an audit. J India Assoc Peadiatr Surg 2004;9:126-30.

[20] Tirabani MV, Gregony T, Reiter BE, et al. Flexibility of thoracoscopic U clip oesophageal anastomosis an alternate for oesophageal reconstruction. Journal of Pediatric Surgery 2004;39(6).

[21] Cudmore RE. Oesophageal atresia and tracheaoesophageal fistula. In: Lister J, Irving IM, eds. Neonatal surgery. London: Butterworth 1990: p. 23158.

[22] Harmon CM, Coran AG. Congenital anomalies of oesophagus. In: Grosfeld JL, O’Neill JA, Fonkalsrud EW, et al, eds. Pediatric surgery. Philadelphia: Mosby 2007: p. 1051-81.

[23] Puri P, Howarth ME. Pediatric surgery. Berlin: Springer 2006: p. 2006-29. 
[24] Sharma S, Sinha SK, Rawat JD, et al. Azygos vein preservation in primary repair of oesophageal atresia with trachea-oesophageal fistula. Pediatr Surg Int 2007;23(12):1215-8.
[25] Upadhyaya VD, Gangopadhyay AN, Gopal SC, et al. Is ligation of azygos vein necessary in primary repair of trachea-oesophageal fistula with oesophageal atresia? Eur J Pediatr Surg 2007;17(4):236-40. 